\title{
Glycolaldehyde disrupts insulin signaling and glucose uptake through adipogenesis
}

\author{
Hee-Weon Lee ${ }^{1}$, Min ji Gu ${ }^{1}$, Jinyoung Hur ${ }^{1}$, Ho-Young Park ${ }^{1}$, Yoonsook Kim ${ }^{1}$ and Sang Keun Ha ${ }^{1,2^{*}}$ (1)
}

\begin{abstract}
The accumulation of advanced glycation end products (AGEs) plays critical roles in exacerbating obesity, arteriosclerosis, cardiovascular disease, diabetes, and their associated complications. Glycolaldehyde (GA) is the metabolic precursor of several AGEs, and its effects vary based on food and cooking methods. Here, 3T3-L1 adipocytes were used to examine the effects of GA on obesity and insulin resistance. We found that GA treatment did not increase lipid accumulation but increased the distribution of adipocyte differentiation. We also investigated the production of receptor for AGEs (RAGE) and reactive oxygen species (ROS) upon GA treatment, as well as the expression levels of peroxisome proliferator-activated receptors $\gamma$ (PPARY), CCAAT enhancer binding protein a (C/EBPa), and CCAAT enhancer binding protein $\beta$ (c/EBP $\beta$ ), which are transcription factors for adipogenesis, were significantly increased upon GA treatment in a concentration-dependent manner. GA arrested the cell cycle at the G0/G1 stage during the early phase of adipogenesis and suppressed the expression of p21 and p27. GA increased the expression of CDK2, phosphorylation of mitogen-activated protein kinases, and secretion of pro-inflammatory cytokines. Overall, these results suggest that GA can stimulate lipid metabolism, hence, we suggest that the stimulation of adipogenesis and insulin resistance by GA may be associated with the interaction between RAGE and adipogenic factors in adipocytes.
\end{abstract}

\section{Highlights}

- Glycolaldehyde treatment remarkably induced the production of RAGE.

- The expression of adipogenic genes was dose-dependently increased by glycolaldehyde.

- Glycolaldehyde increased the ROS production and inflammatory responses.

- Glycolaldehyde disrupted mitochondrial function and glucose uptake.

Keywords: Advanced glycation end products, RAGE, Glycolaldehyde, Obesity, Glucose uptake

\section{Introduction}

Maillard reaction is a non-enzymatic reaction between reducing sugars and amino structures in amino acids, proteins, phospholipids, or DNA and is associated with age and severity of diabetes. Following the reversible formation of Schiff bases between carbonyl and free amino

\footnotetext{
*Correspondence: skha@kfri.re.kr

1 Korea Food Research Institute, 245, Nongsaengmyeong-ro, Iseo-myeon,

Wanju-gun, Jeollabuk-do 55365, Republic of Korea

Full list of author information is available at the end of the article
}

groups, irreversible advanced glycation end products (AGEs) were formed [1, 2]. Aldehydes, such as glycolaldehyde (GA) and glyceraldehyde, have also been shown to induce AGE formation. Although several studies have investigated the properties of these protein modifications, many components, including GA, have not been established in murine 3T3-L1 adipocytes.

GA concentrations in adipose tissue from healthy people or patients have not been quantified so far. Although the GA level of adipose tissue has not been quantified, its physiological concentration is estimated to range from 
0.2 to $2 \mathrm{mM}$ and several in vitro studies have employed this range. Many previous studies have been conducted in various cell models at concentrations ranging from 0.2 to $2 \mathrm{mM}$. We have also checked the reasonable reasons for the various concentrations used in many previous studies. Based on this, we performed the screening in the adipocyte cell model using concentrations ranging from 0.2 to $2 \mathrm{mM}$. The production and accumulation of AGEs require large amounts of GA with steady accumulation in the adipose tissue. Therefore, we applied an acute model to study adipogenesis caused by GA-derived AGEs at the cellular level.

Protein modifications through derivatization by GA may induce chronic diseases through specific receptors interaction, such as receptor for advanced glycation end products (RAGE). Some AGEs, such as $\mathrm{Ne-(Carboxymethyl)lysine} \mathrm{(CML)} \mathrm{and}$ $\mathrm{N} \varepsilon$-carboxyethyl-lysine (CEL), are well-studied in diabetes and chronic inflammation caused by the interaction of AGE and RAGE [3, 4]. However, it remains unclear in GA. The interaction between AGE and RAGE induces numerous signaling pathways, such as the NADPH oxidase (NOX) pathway and Reactive oxygen species (ROS) production [5, 6]. ROS production regulates adipocyte differentiation and is a major causing factor in diabetes through chronic lipid accumulation. However, it is unclear whether AGE formation via GA influences this process [7]. The continuous exacerbation of obesity causes diabetes; AGEs are associated with the regulation of RAGE and production of ROS in obesity and diabetes $[8,9]$.

During adipogenesis, in which lipid accumulation occurs, transcription factors play critical roles. In this model, CCAAT/enhancer binding protein $(\mathrm{C} / \mathrm{EBP}) \beta$ and $\delta$ induce the expression of peroxisome proliferator-activated receptor gamma (PPAR $\gamma$ ). According to previous studies, the endogenous expressions of $\mathrm{C} /$ EBP $\beta$ and $\delta$ precede that of PPAR $\gamma$, and the former's ectopic expression results in the latter's induction [10]. This induction may be a direct effect of transcription through the C/EBP binding site at the PPAR $\gamma$ promoter [11]. Since ROS plays a key role in this process, it is therefore important to investigate the effects of RAGE expression and ROS production. In addition, adipocyte differentiation is known as an inflammatory respose, and inflammatory cytokines have been shown to be secreted through adipogenesis and mitogen-activated protein kinase (MAPK) phosphorylation [12, 13].

Adipocyte differentiation processes, including the effects of ROS production, cause insulin resistance. Furthermore, mitochondrial dysfunction has been associated with type 2 Diabetes Mellitus (T2DM)-related insulin resistance. Glucose and lipid metabolism disorders lead to defects in insulin signaling associated with various pathological conditions $[14,15]$. Thus, the elucidation of the molecular and cellular mechanisms of underlaying insulin resistance will expand our understanding of the etiology of various diseases [16].

The aim of this study is to examine the effects of RAGE expression and ROS production on adipogenesis and insulin resistance in 3T3-L1 adipocytes. Our findings show that GA induces obesity and insulin resistance through the AGE-RAGE axis and ROS signaling in the adipogenesis process.

\section{Materials and methods}

\section{Chemical reagents and antibodies}

GA was obtained from Sigma-Aldrich (St. Louis, MO, USA). Dulbecco's modified Eagle's medium (DMEM), fetal bovine serum (FBS), and bovine calf serum were obtained from Gibco (BRL, Carlsbad, USA). Almost all chemicals, including isobutyl-3-methylxanthine (IBMX), dexamethasone, and insulin were obtained from Sigma Chemical Co. unless otherwise stated. GA was dissolved in distilled water and diluted at the indicated concentrations. Antibodies against target molecules were purchased from Cell signaling (Danvers, MA, USA) and Santa Cruz Biotechnology (Santa Cruz, CA, USA).

\section{Cell culture and differentiation assay}

The 3T3-L1 cell line was purchased from ATCC (Manassas, VA, USA). Preadipocytes were sustained in DMEM (Gibco, Carlsbad, USA) supplemented with $10 \%$ heat-inactivated bovine calf serum. The 3T3-L1 cells were incubated at $37^{\circ} \mathrm{C}$ in a fully humidified incubator containing $5 \% \mathrm{CO}_{2}$. 3T3-L1 cells were seeded on a 6 -well culture plate at a density of $2 \times 10^{5}$ cells/ well and incubated for confluence for 4 days, and then treated MDI (methylisobutylxanthine, dexamethasone, and insulin) in DMEM containing 10\% FBS for 2 days. On day 2, the culture medium was replaced with DMEM containing 10\% FBS supplemented with insulin $(5 \mu \mathrm{g} / \mathrm{mL})$. This medium was replaced every 2 days. GA was maintained in the culture medium at a concentration of $0.1,1$, or $10 \mu \mathrm{g} / \mathrm{mL}$ during adipocyte differentiation. On day 7 , the cells were collected using centrifugation (Eppendorf Centrifuge 5424R, Hamburg, Germany) at $12,000 \mathrm{~g}$ for $5 \mathrm{~min}$ at $4{ }^{\circ} \mathrm{C}$, and the pellets were lysed using a homogenizer buffer.

\section{Oil Red O staining}

Following adipocyte differentiation, adipocytes were rinsed with phosphate-buffered saline (PBS) and fixed with $3.7 \%$ formalin for $10 \mathrm{~min}$ at room temperature 
$\left(15-20{ }^{\circ} \mathrm{C}\right)$. The fixed cells were rinsed several times with PBS and incubated with Oil Red O staining solution for $2 \mathrm{~h}$ at room temperature. The Oil Red $\mathrm{O}$ solution was removed, and cells were rinsed several times with PBS. The images of lipid accumulation were detected using an optical microscope (ZEISS, Oberkochen, Germany). The dye retained in the cells was eluted with isopropanol and determined using spectrophotometric analysis at $540 \mathrm{~nm}$.

\section{ROS production assay}

ROS production was quantified by fluorescence microscopy (ZEISS, Oberkochen, Germany) using a $2^{\prime}, 7^{\prime}$-dichlorofluorescein diacetate probe (DCF-DA). 3T3-L1 cells were incubated with $10 \mu \mathrm{M}$ of DCF-DA under dark conditions for $30 \mathrm{~min}$ at $37^{\circ} \mathrm{C}$, and rinsed with phosphate-buffered saline (PBS). ROS production was measured using an ELISA plate reader (Molecular Devices) at $488 \mathrm{~nm}$ excitation and $522 \mathrm{~nm}$ emission wavelengths.

\section{Immunoblotting assay}

3T3-L1 cells were plated at $2 \times 10^{5}$ cells/well of 6 -well tissue plates. Preadipocytes were treated with MDI or insulin in the presence or absence of GA $(1,10$, or $100 \mu \mathrm{M})$ for 7 days. The cultured cells were rinsed in PBS and suspended in a homogenizer lysis buffer. The supernatant was collected after centrifugation for 5 min at $12,000 \mathrm{~g}$ at $4{ }^{\circ} \mathrm{C}$. The protein concentration was determined using a bradford assay kit (Bio-Rad Lab, Hercules, CA, USA) with bovine serum albumin as the standard. The whole cell lysates were separated by 6-15\% SDS-PAGE and transferred to a nitrocellulose (NC) membrane (Bio-Rad Lab, Hercules, CA, USA). The membrane was blocked with $5 \%$ skim milk in trisbuffered saline containing $0.2 \%$ Tween 20 (TBST) at room temperature for $1 \mathrm{~h}$, and the membranes were probed with the appropriate primary (1:500) and secondary (1:5000) antibodies. These blots were developed using an enhanced chemiluminescence kit. The following antibodies were used: AKT (\#9272), PI3K (\#4255), IRS-1 (\#2382), p38 (\#8690), phospho-p38 (\#9211), JNK (\#9258), phospho-JNK (CST \#9251), ERK (\#4691); all from Cell Signaling Technologies (Danvers, MA, USA), mtDNA (sc166965), IL-6 (sc57315), TNF- $\alpha$ (sc52746), SREBP-1c (sc365113), c/EBP $\quad$ (sc7692), phospho- c/EBP $\beta$ (sc398753), CDK2 (sc6248), p21 (sc397), c/EBP $\alpha$ (sc365318); all from Sigma aldrich (St. Louis, MO, USA), Adiponectin (ab22554), Leptin (ab16227), GLUT4 (ab33780); all from abcam (Cambridge, UK).

\section{Flow cytometry analysis}

The cell cycle arrest was investigated using Fluorescenceactivated cell sorting (FACs). Preadipocytes were incubated with MDI in the presence or absence of GA for $24 \mathrm{~h}$. The cells were collected and incubated by overnight suspension in $70 \%$ ethanol at $4{ }^{\circ} \mathrm{C}$. After fixing of adipocyte, cells were stained with $50 \mu \mathrm{g} / \mathrm{mL}$ of propidium iodide solution containing RNase $(10 \mu \mathrm{g} / \mathrm{mL})$ for $1 \mathrm{~h}$ in the dark condition. FACs analysis was performed on CytoFLEX S Flow Cytometer instrument, and data analysis with using Kaluza Analysis Software (BECKMAN COULTER, Indianapolis, IN, USA).

\section{RNA extraction and reverse transcription-polymerase chain reaction ( $R T-P C R)$}

The mRNA expressions of several genes were measured by qRT-PCR. After GA treatment, total RNA was isolated from cultured cells using Trizol (Sigma, St. Louis, USA), according to the manufacturer's instructions, and used for cDNA synthesis. qRT-PCR was performed using adipogenic-related factors, and cytokine-specific primers. cDNA was amplified in $20 \mu \mathrm{L}$ of PCR reaction mixture $(1 \mu \mathrm{L}$ each of forward and reverse primer, $8 \mu \mathrm{L}$ of cDNA synthesis solution in pure water, and $10 \mu \mathrm{L}$ of

Table 1 Primer sequences

\begin{tabular}{|c|c|c|}
\hline Gene & Forward primer $\left(5^{\prime} \rightarrow 3^{\prime}\right)$ & Reverse primer $\left(5^{\prime} \rightarrow 3^{\prime}\right)$ \\
\hline PPARY & GCC CTTTGG TGA CTTTAT GGA & GCA GCA GGTTGT CTT GGA TG \\
\hline $\mathrm{C} / \mathrm{EBPa}$ & GCG AGC ACG AGA CGT CTA TAG & GCC AGG AAC TCG TCG TTG AA \\
\hline TNF- $a$ & CCC TCA CAC TCA GAT CAT CTT CT & GCT ACG ACG TGG GCT ACA G \\
\hline IL-6 & CCA CGG CCTTCC CTA CTTC & TTG GGA GTG GTA TCC TCT GTG A \\
\hline $\mathrm{aP2}$ & GAA CCT GGA AGC TTG TCT CCA GTG & GAT GCT CTT CAC CTT CCT GTC GTC TGC \\
\hline LPL & TTG CGC CTC CTG CTC AA CCC & CCC CTC CTC GGA AGG CGG TC \\
\hline FAS & CTG AGA TCC CAG CAC TTC TTG & GCC TCC GAA GCC AAA TGA \\
\hline SREBP-1C & GGC TAT TCC GTG AAC ATC TCC TA & ATC CAA GGG CAT CTG AGA ACT \\
\hline GAPDH & TGC ATC CTG CAC CAC CAA & TCC ACG ATG CCA AAG TTG TC \\
\hline
\end{tabular}


SYBR Green Master Mix) in a quantitative real-time PCR system. Fluorescence was measured at each cycle. The RT-PCR primer sequences used to identify the expression of various genes are listed in Table 1.

\section{ATP production assay}

ATP production was measured by using ATP determination kit (Molecular Probes, USA). It is a bioluminescence assay for quantitative determination of ATP using recombinant firefly luciferase and its substrate D-luciferin. Cells after respective treatments were rinsed with phosphatebuffered saline (PBS) and lysed in ATP-releasing buffer containing $100 \mathrm{mM}$ potassium phosphate buffer at $\mathrm{pH}$ 7.8, 2 mM EDTA, $1 \mathrm{mM}$ dithiothreitol (DTT), and $1 \%$ Triton X-100 [17]; $20 \mu \mathrm{L}$ of cell lysate were mixed with $180 \mu \mathrm{L}$ of standard reaction mixture containing $8.9 \mathrm{~mL}$ distilled water, $0.5 \mathrm{~mL} 20 \times$ reaction buffer, $0.1 \mathrm{~mL} 0.1 \mathrm{M}$ DTT, $0.5 \mathrm{~mL}$ of $10 \mathrm{mM}$ D-luciferin, $2.5 \mu \mathrm{L}$ of firefly luciferase $(5 \mathrm{mg} / \mathrm{mL}$ stock solution) and luminescence was measured in ELISA plate reader. ATP concentrations in the samples were calculated from standard ATP curve and normalised to the protein content. Cells treated with oligomycin $(8 \mu \mathrm{M}$ for $8 \mathrm{~h})$ was used as the positive control for measuring depletion in ATP content due to mitochondrial dysfunction [18].

\section{2-Deoxy glucose uptake assay}

2-deoxy glucose (2-DG) uptake assay was carried with glucose uptake colorimetric assay kit (Abcam, Cambridge, MA, USA) according to the manufacturer's instructions using RG (100 nM) as the positive control. Briefly, cells were seeded in 96 well plate and differentiated to mature adipocytes and treated as above. Then the cells were starved for glucose by preincubating in Krebs-Ringer-Phosphate-Hepes (KRPH) buffer containing 2\% BSA for $40 \mathrm{~min}$. Cells were stimulated with insulin $(10 \mu \mathrm{g} / \mathrm{mL})$ for $20 \mathrm{~min}$ and treated with 2-DG, mixed and incubated for $20 \mathrm{~min}$. In principle 2-DG can be taken up by glucose transporters and metabolized to 2-DG6-phosphate (2-DG6P) and cannot be further metabolized, and thus accumulates in the cells. The NADPH generated from oxidised 2-DG6P was finally measured by an enzymatic recycling amplification reaction, which is directly proportional to 2-DG uptake by the cells.

\section{JC-1 staining}

Mitochondrial membrane potential was examined by staining adipocytes with the tetraethylbenzimidazolylcarbocyanine iodide (JC-1), a cationic dye that accumulates in the normal mitochondria. JC-1 staining dye $(10 \mu \mathrm{M})$ was treated to culture plate $1 \mathrm{~h}$, and then the adipocytes were rinsed with the dilution buffer. Fluorescence images were photographed using a LSM 900 fluorescence microscope (ZEISS, Oberkochen, Germany).

\section{Mitochondrial membrane potential assay}

Mitochondrial membrane potential was measured using mitochondrial staining kit, JC-1. The experiment was done as per the protocol provided with the kit (JC-1 kit, Sigma). The kit uses the cationic, lipophilic dye, JC-1. In normal cells, due to the electrochemical potential gradient, the dye concentrates in the mitochondrial matrix, where it forms red fluorescent aggregates (JC-1 aggregates). Any event that dissipates the mitochondrial membrane potential prevents the accumulation of the JC-1 dye in the mitochondria and thus, the dye is dispersed throughout the entire cell leading to a shift from red (JC-1 aggregates) to green fluorescence (JC- 1 monomers). The cells after respective treatments were incubated with JC-1 staining solution for $20 \mathrm{~min}$ at $37{ }^{\circ} \mathrm{C}$. The stain was washed off with PBS and examined under spinning disk microscope and images were collected and fluorescence intensity was also measured. For JC-1 monomers, the fluorescence was measured at $490 \mathrm{~nm}$ excitation and $530 \mathrm{~nm}$ emission wavelengths, and for JC-1 aggregates, the fluorescence was measured at $525 \mathrm{~nm}$ excitation and $590 \mathrm{~nm}$ emission wavelengths.

\section{Statistical analyses}

For each experiment, data were obtained in triplicates and reported as mean \pm SEM. Comparisons between GA-stimulated cells and untreated control cells were conducted by ANOVA and Student's $t$-test. Significant values are indicated by an asterisk ( $" p<0.05)$.

\section{Results}

\section{Glycolaldehyde increased the RAGE and ROS production} and lipid accumulation in 3T3-L1 cells

The AGEs produced by GA can mediate numerous pathways through specific receptors, such as RAGE, and activate downstream pathways, including various signaling cascades and ROS. In addition, ROS is a critical factor that influences adipocyte differentiation and insulin resistance. GA increased the expression of RAGE in MDI-induced adipocytes as shown by western blot analysis. In addition, when GA was treated simultaneously, the expression level of RAGE was up-regulated in a concentration-dependent manner. Compared with the MDIinduced group, treatment with GA increased the RAGE protein level by more than 3.2 times (Fig. 1A). As shown in Fig. 1B, intracellular formation of ROS was measured using DCFDA staining. GA increased ROS production via AGE-RAGE interaction in 3T3-L1 cells. Adipocyte differentiation was also induced by GA treatment. However, the amount of lipid accumulation remained 


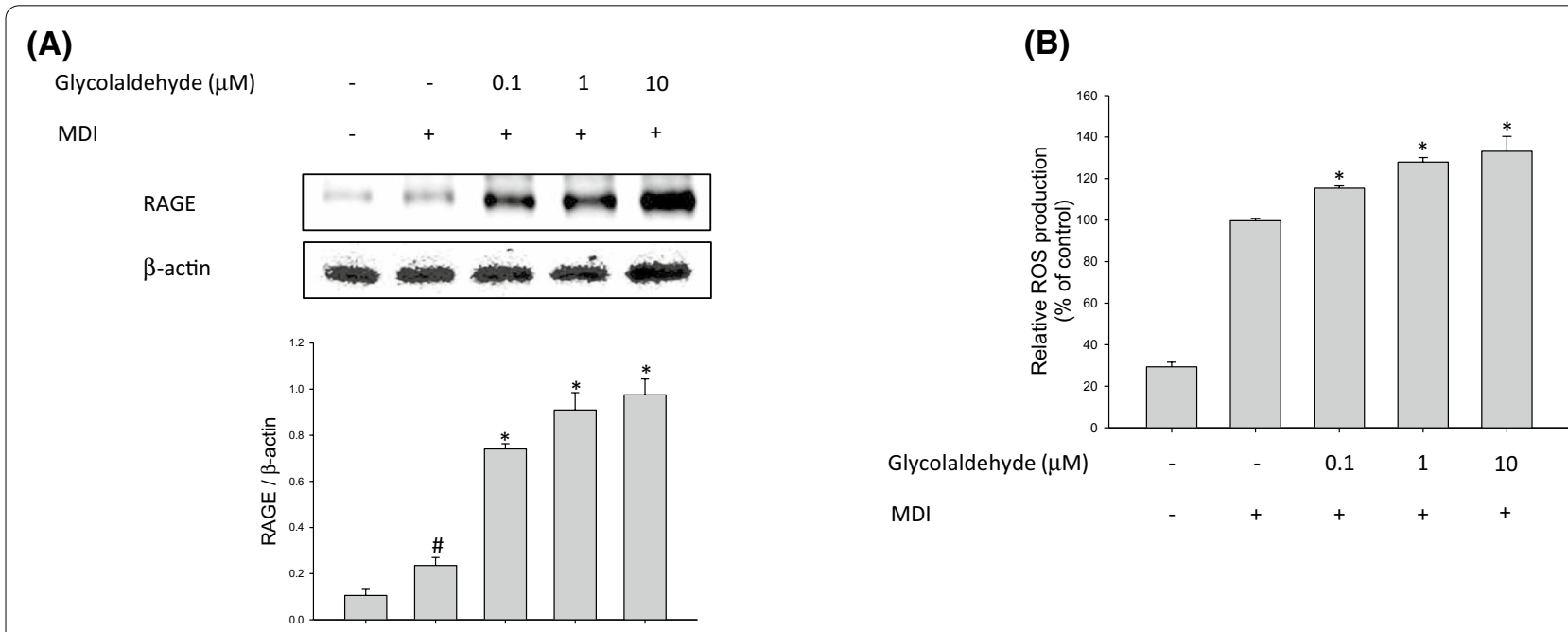

(C)

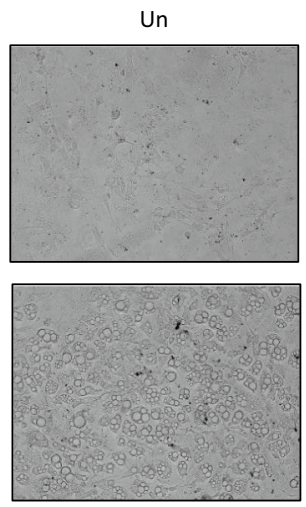

MDI + GLY 0.1
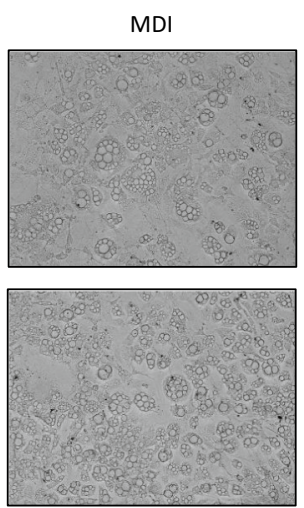

$\mathrm{MDI}+\mathrm{GLY} 1$
GLY 10
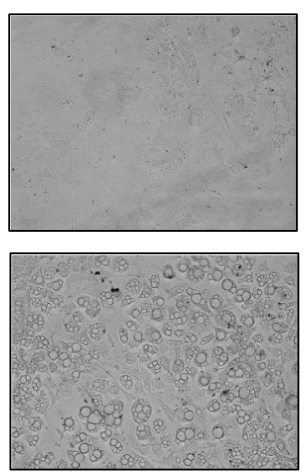

$\mathrm{MDI}+\mathrm{GLY} 10$
(D)

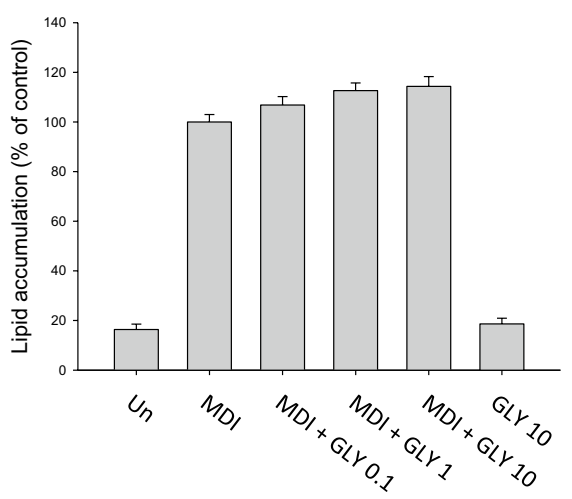

Fig. 1 Effect of glycolaldehyde on RAGE and ROS production and lipid accumulation in 3T3-L1 cells. A 3T3-L1 cells were stimulated with MDI in the presence or absence of glycolaldehyde (GA; $0.1,1$, and $10 \mu \mathrm{M})$ for $2 \mathrm{~h}$. Cell lysates were collected and subjected to western blotting using antibodies against the target gene RAGE. B ROS level was determined as described in materials and methods. Adipocytes were treated with DCF-DA (10 $\mu M$ ) in the presence or absence of GA $(0.1,1$, and $10 \mu \mathrm{M})$ for $30 \mathrm{~min}$ (Glycolaldehyde; GLY). C, D Confluent 3T3-L1 cells were treated with MDI containing $\mathrm{GA}(0.1,1$, and $10 \mu \mathrm{M})$ at the early phases of adipocyte differentiation. Adipocytes were then stained with Oil Red O on day 7. RAGE level was measure by western blotting with $\beta$-actin as internal control. Data presented as mean \pm SEM. ${ }^{*} p<0.05$ vs. MDI treatment

unchange, while the number of differentiated cells was increased (Fig. 1C, D).

\section{Glycolaldehyde induced the expression of adipogenic factors during adipogenesis in 3T3-L1 cells}

During adipocyte differentiation, adipogenic transcription factors and genes associated with adipogenesis are essential. In particular, PPAR $\gamma$ and $c / E B P \alpha$ act an essential role in the late phase of adipogenesis process by regulating several adipogenic factors associated with lipid metabolism. Therefore, we examined the effect of GA on the expressions of critical transcription factors. The expression levels of adipogenic transcription factors and genes, including PPAR $\gamma$ and $c / E B P \alpha$, were measured using western blot and qRT-PCR. As shown in Fig. 2A and B, GA significantly increased the protein levels of PPAR $\gamma$ and $\mathrm{c} / \mathrm{EBP} \alpha$ and their mRNA expression levels in a concentration-dependent manner (Fig. 2C, D). Furthermore, we investigated the expression levels of adipogenic factors involved in adipogenesis and accumulation through involvement in synthesis and transport of fatty acid and triglyceride. GA increased the 
(See figure on next page.)

Fig. 2 Effect of glycolaldehyde on adipogenic factors during adipocyte differentiation in 3T3-L1 cells. A, B Confluent 3T3-L1 cells were differentiated in the presence or absence of glycolaldehyde (GA; $0.1,1$, and $10 \mu \mathrm{M}$ ) for 7 days. 3T3-L1 adipocytes were lysed and collected for Western blotting with $\beta$-actin as internal control. Protein levels were quantified using densitometric scanning. C, D mRNA expression levels of PPARY and c/EBPa were determined by qRT-PCR. E-H Expression levels of aP2, LPL, FAS, and SREBP-1c mRNA were determined by qRT-PCR. GAPDH was used as an internal control. Data presented as mean \pm SEM. ${ }^{*} p<0.05$ vs. MDI treatment

mRNA expression levels of adipocyte fatty acid binding protein (aP2), lipoprotein lipase (LPL), fatty acid synthetase (FAS), and SREBP-1c (Fig. 2E-H). These data indicate that GA could stimulate adipocyte differentiation through the regulation of adipogenic transcription factors and genes. Taken together, we speculate that GAstimulated adipocyte differentiation depends on ROS production and AGE-RAGE interaction through the increased expression of RAGE.

\section{Glycolaldehyde induced the mitotic clonal expansion at the early phase of adipogenesis in 3T3-L1 cells}

In adipogenesis process, the mitotic clonal expansion (MCE) phase acts as an important factor in adipogenesis. In general, preadipocytes cultured to confluence became growth-arrested at the G0-to-G1 cell cycle during adipogenesis, and then preadipocytes re-entered the cell cycle upon induction of hormones. Therefore, we identified cell cycle factors that regulate the cell cycle at MCE phase. MCE is an important procedure during the early phase of adipogenic differentiation. To investigate the effect of GA on MCE, we examined the changes of the cell cycle in the absence or presence of GA. Following 3T3-L1 cells incubation with MDI, exposure to GA $(10 \mu \mathrm{M})$ resulted in cell cycle arrest at the G0/G1 phase. The protein expressions of cell cycle-related proteins $\mathrm{p} 21$, p27, and CDK2 were regulated by GA. The levels of p21 and p 27 were decreased following GA treatment, whereas that of CDK2 was increased. These findings showed that the synergic effect of GA can occur in the early process of adipocyte differentiation by the stimulation of MCE caused by cell cycle arrest at the G0/G1phase (Fig. 3A, B).

In the MCE phase, $c / E B P \beta$ is activated, which is a necessary process in the early phase of adipocyte differentiation. MCE also activates several genes that cause lipid accumulation through adipogenesis. Therefore, we determined the effect of GA on the c/EBP $\beta$, a major transcription factor, and on the various factors that play a role in differentiation. GA increased the expression levels of SREBP-1c, FAS, adiponectin, and leptin. GA also induced c/EBP $\beta$ phosphorylation in 3T3-L1 cells (Fig. 3C). These data indicated that the regulation of cell cycle and adipogenesis-related genes by GA are important in the early phase of adipogenesis.

\section{Glycolaldehyde increased the activation of MAPKs and pro-inflammatory cytokines in 3T3-L1 cells}

MAPKs are a well-known factor involved in the early stages of adipogenesis. In addition, inflammatory cytokines are excessively generated during adipogenesis in which sufficient fat is accumulated, which adversely affects adipogenesis and metabolic diseases. MAPKs are an important factor in the regulation of metabolic disorders, such as inflammatory diseases and diabetes. We further investigated whether MAPKs affect the effects of GA in adipocyte differentiation. GA significantly increased MAPKs phosphorylation compared with MDI treatment alone (Fig. 4A).

Next, to investigate the production of pro-inflammatory cytokines in MDI-induced 3T3-L1 cells, we used western blot and qRT-PCR to determine the expression levels of inflammatory cytokines. Inflammatory cytokines are increased in adipogenesis, leading to inflammatory metabolic disorders, such as diabetes and associated complications. We proved that treatment with GA increased the levels of TNF- $\alpha$ and IL-6 (Fig. 4B-D). Collectively, these findings indicated that GA caused the production of inflammatory cytokines throughout adipocyte differentiation.

\section{Glycolaldehyde disrupted the insulin signaling and mitochondrial function in 3T3-L1 cells}

Mitochondrial biogenesis and activity are dramatically increased during adipogenesis, which plays an important role in organelles. Furthermore, mitochondria in differentiated adipocytes are associated with fatty acid oxidation, adipokine secretion, and dysregulation of glucose homeostasis. Therefore, mitochondrial dysfunction is an important etiology of metabolic disorders such as obesity and insulin resistance. To investigate the mechanism by which GA disturbs mitochondrial function, insulin signaling and glucose transporter 4 (GLUT4) were evaluated using western blot analysis. Insulin signaling is initiated by phosphorylation and activation of tyrosine residues of insulin receptor substrate (IRS) proteins by an insulin receptor (IR) having tyrosine kinase activity. In addition, phosphorylated IRS binds to PI3K and transmits the signal of insulin. PI3K plays an essential role in amplifying insulin signals through the activation of the AKT 
(A)

Glycolaldehyde $(\mu \mathrm{M})$

MDI
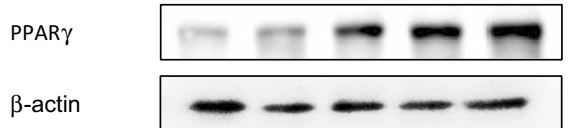

$\beta$-actin

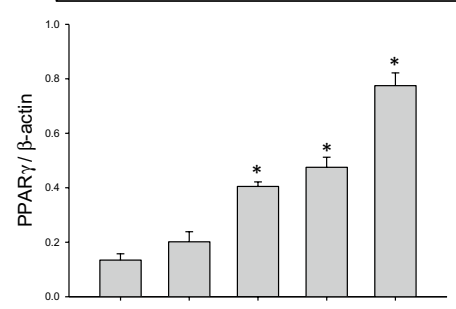

(C)

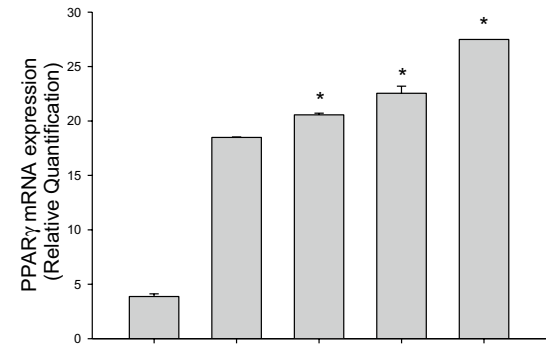

Glycolaldehyde $(\mu \mathrm{M})$

MDI

(E)

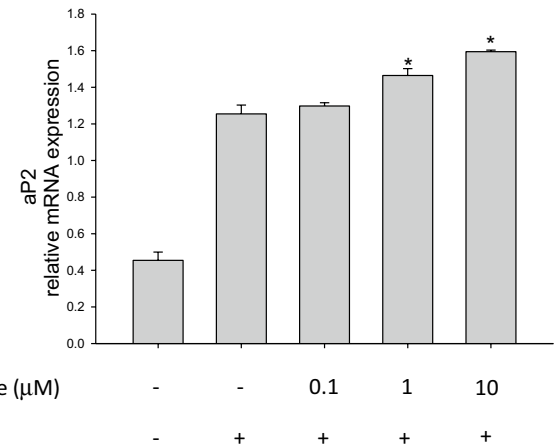

(G)

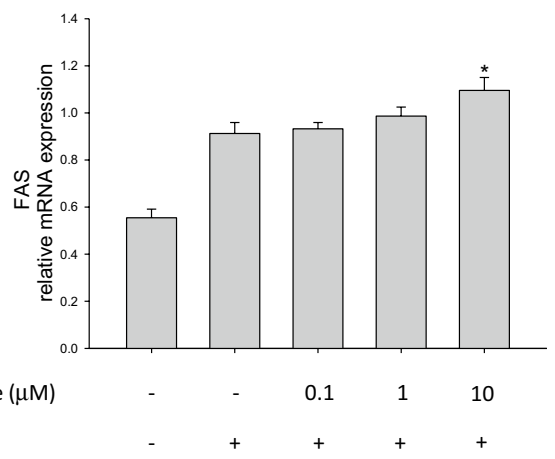

(B)

Glycolaldehyde $(\mu \mathrm{M})$

MDI
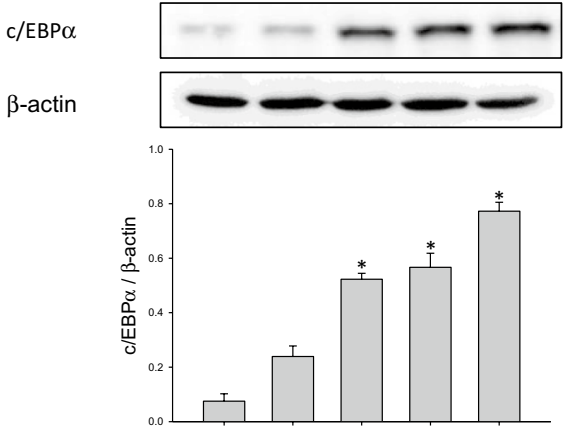

(D)

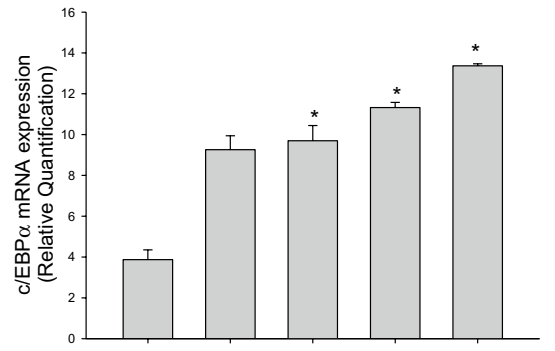

Glycolaldehyde ( $\mu \mathrm{M})$

MDI

(F)

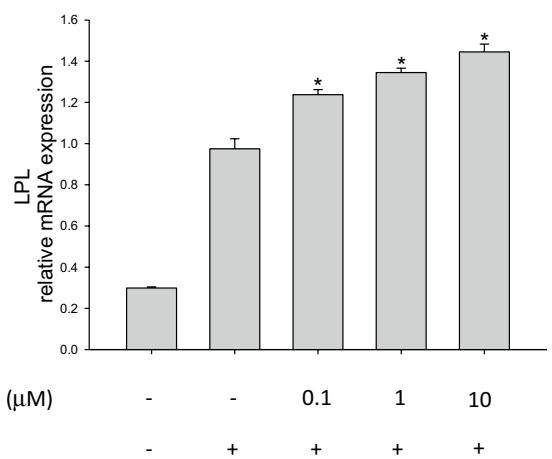

(H)

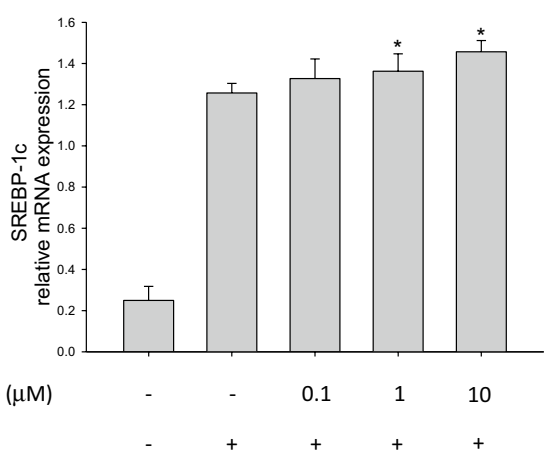

Fig. 2 (See legend on previous page.) 


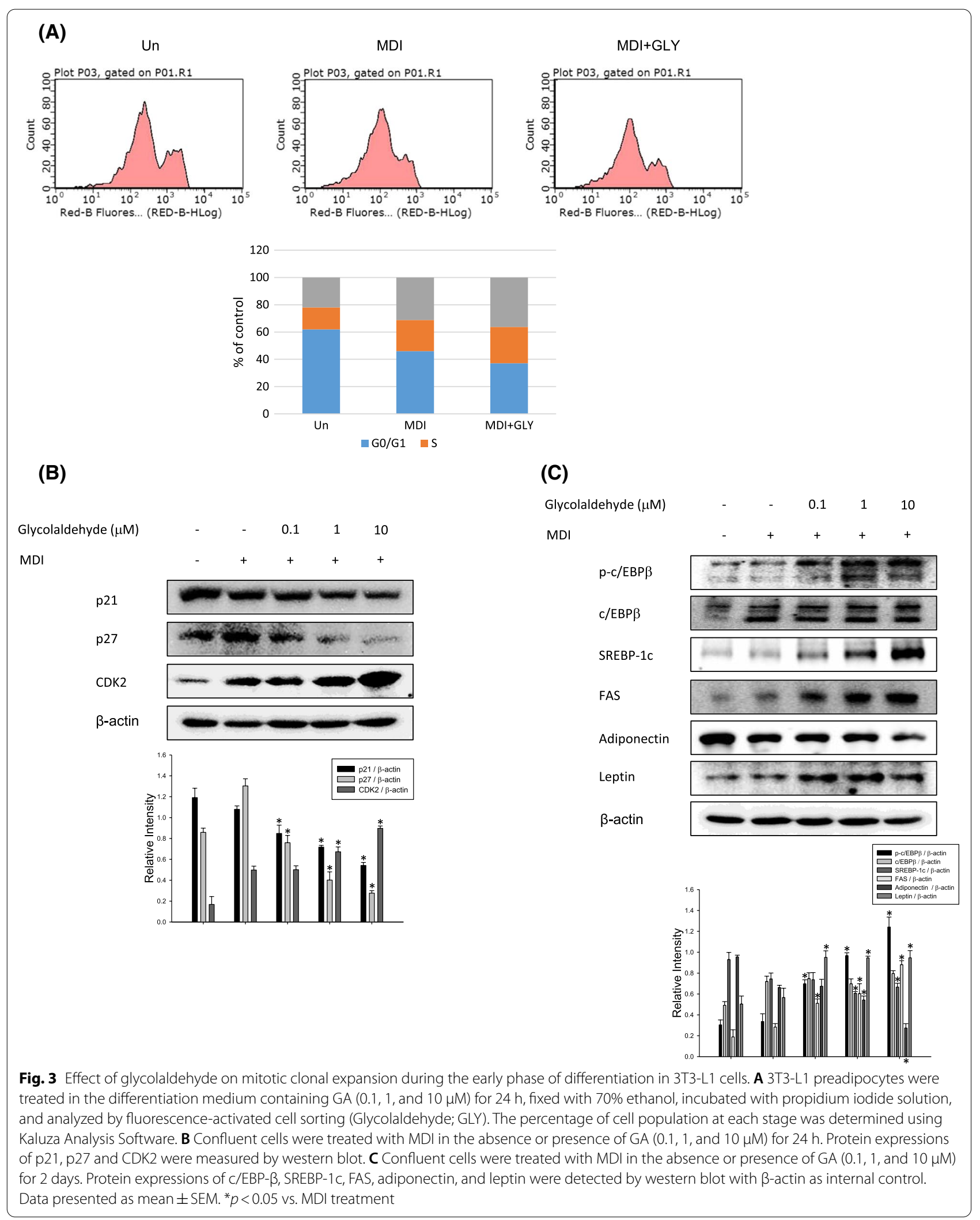


(A)

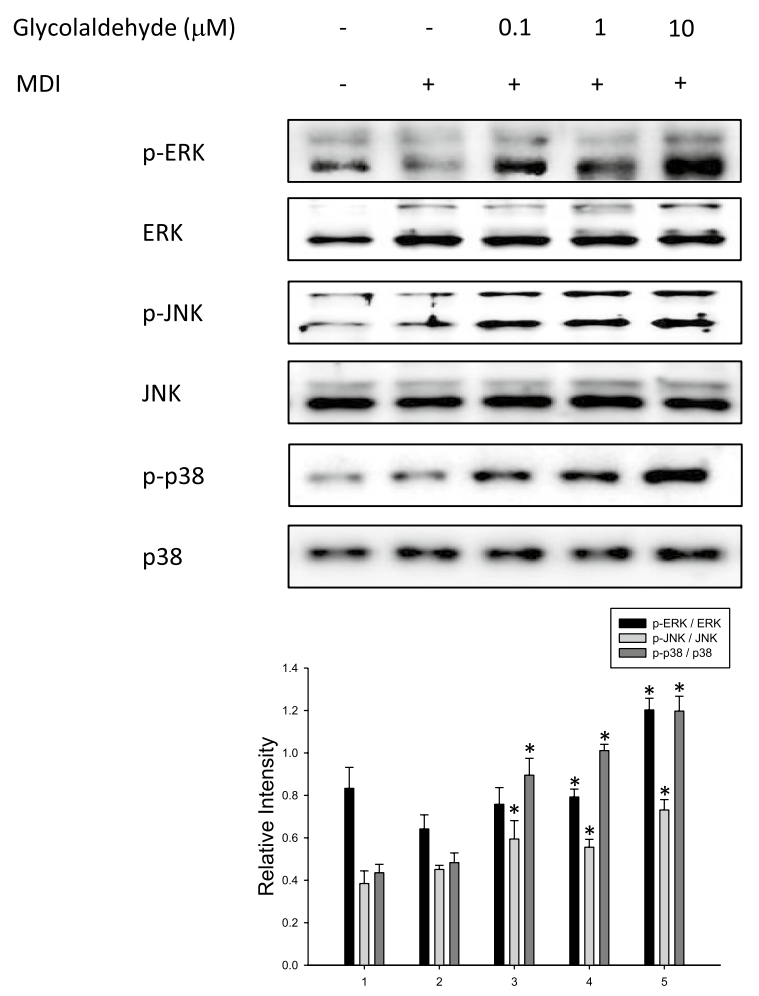

(C)

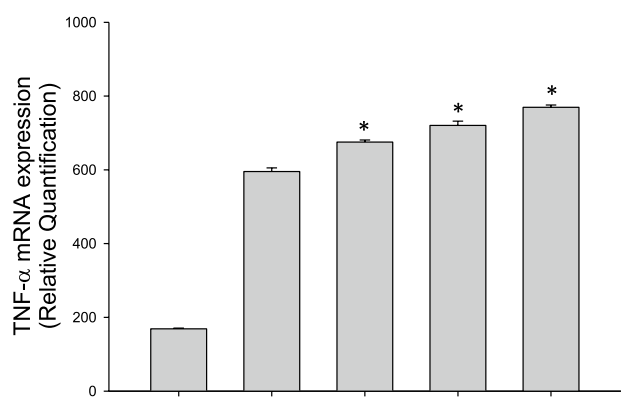

Glycolaldehyde $(\mu \mathrm{M})$

MDI

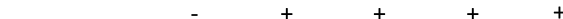
the target genes ( $p-J N K, J N K, p-p 38, p 38, p$-ERK, and ERK). B Adipocytes were sustained in the differentiation medium containing the various concentrations of GA for 7 days. Expressions of TNF- $\alpha$ and IL- 6 were measured by western blotting with $\beta$-actin as internal control. C, D mRNA expression levels of TNF-a and IL-6 were determined by qRT-PCR. Data presented as mean \pm SEM. ${ }^{*} p<0.05$ vs. MDI treatment

cascade. After GA treatment, phosphotyrosine attenuation on IRS-1 and inactivation of PI3K were observed. In addition, the inactivation of PI3K was indicated by the inhibition of AKT activation of insulin signaling pathway (Fig. 5A). These results indicate that treatment with
(B)

$\begin{array}{llllll}\text { Glycolaldehyde }(\mu \mathrm{M}) & - & - & 0.1 & 1 & 10 \\ \mathrm{MDI} & - & + & + & + & +\end{array}$

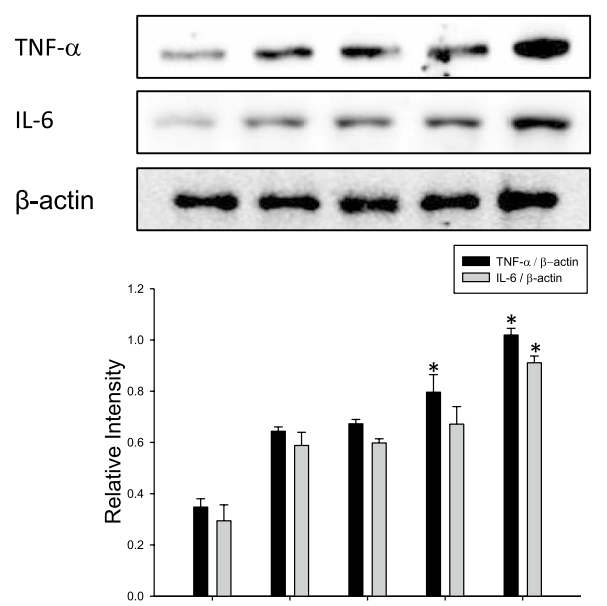

(D)

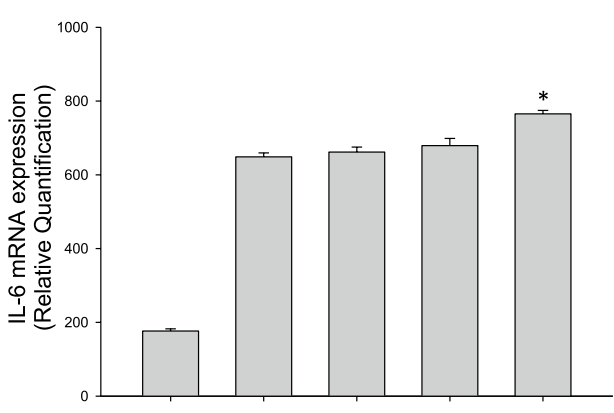

Glycolaldehyde $(\mu \mathrm{M})$

MDI 
(See figure on next page.)

Fig. 5 Effect of glycolaldehyde on insulin signaling and mitochondrial dysfunction in 3T3-L1 cells. A Confluent 3T3-L1 cells were cultured in the differentiation medium containing the indicated concentrations of GA for 7 days. Expressions of IRS-1, PI3K, and AKT were analyzed by western blotting with $\beta$-actin as internal control. B Confluent 3T3-L1 cells were simulated to differentiate with MDI in the absence or presence of GA (0.1, 1 , and $10 \mu \mathrm{M}$ ) for 2 days. Cell lysates were harvested and subjected to western blotting analysis using antibodies against target molecules (mtDNA and GLUT4). C The relative fluorescence intensities of the mitochondrial biogenesis (MitoBiogenesis ${ }^{\mathrm{TM}}$ In-Cell ELISA Kit, ab110217), D ATP production (ATP Assay Kit, 119,107), and E mitochondrial membrane potential (JC-1-Mitochondrial Membrane Potential Assay Kit, ab113850) in various groups; un, MDI treated group, MDI + GA cotreated group. Data are expressed as the mean \pm SEM of three independent experiments. ${ }^{*} p<0.05$ vs. $\mathrm{MDI}$ treatment

this process. Therefore, we measured the levels of mitochondrial DNA (mtDNA) and GLUT4 involved in glucose uptake and mitochondrial function in fully differentiated 3T3-L1 adipocytes. GA remarkably reduced the expression of mtDNA and GLUT4 in fully differentiated 3T3-L1 adipocytes (Fig. 5B). As illustrated in Fig. 5C, GA treatment showed marked suppressions in Mito-Biogenesis compared with MDI-treated cells. To confirm the functional reduction of mitochondria by GA, we investigated adenosine triphosphate (ATP) production and mitochondrial membrane potential (MMP) in fully differentiated 3T3-L1 adipocytes and found that GA significantly reduced the levels of ATP production and MMP in mitochondria (Fig. 5D, E).

Collectively, our results are consistent with previous reports that mitochondrial dysfunction affects insulin sensitivity and glucose uptake $[19,20]$. These results show that the continuous accumulation of lipid during adipocyte differentiation causes mitochondrial dysfunction and further restricts the absorption of glucose by inhibiting insulin signaling. In this process, GA exacerbates the normal function of the mitochondria and the insulin signals in adipocytes.

\section{Inhibition of GA induced adipogenesis and insulin resistance}

To determine the regulation of adipogenesis and insulin resistance related factors in GA-stimulated 3T3-L1 cells, the effect of siRAGE on important factors induced by GA was investigated. As shown in Fig. 6A, when preadipocytes were incubated with siRAGE prior to GA exposure, adipogenic factors and insulin signaling related fators were regulated. These results indicate that RAGE is an important initial factor that regulates the downstream signaling of metabolic diseases in adipocytes. Additionally, ROS is a critical factor inducing RAGE production and exacerbating metabolic diseases through inflammatory action. To assess the role of ROS in GA-stimulated 3T3-L1 cells, we treated cells with $\mathrm{N}$-acetyl-L-cysteine (NAC), a ROS production inhibitor and examined protein expression of adipogenic and insulin signaling related factors using western blot analysis. The results showed that GA induced metabolic dysfunction and that the levels of these factors regulated after incubation with GA were decreased in adipocytes pretreated with NAC (Fig. 6B). Collectively, these data suggest that RAGE and ROS signaling pathways are associated with metabolic dysfunction mediated gene expression, and that RAGE and ROS inhibitors block exacerbation of metabolic dysfunction through inhibition of RAGE and ROS signaling pathways.

\section{Discussion}

Maillard reaction is a type of non-enzymatic browning that reduces carbonyl and carbonyl compounds, especially sugars, using free amino groups, such as amino acids, amines, and proteins [21]. This study reports for the first time that GA, a precursor of the AGEs produced by the Maillard reaction, promotes adipocyte differentiation and interferes with insulin signaling in adipocytes [22]. We have demonstrated that the increased expression level of RAGE and production of ROS by GA treatment were associated with lipid metabolism. Meanwhile, previous studies have shown that GA affects various diseases and disorders, such as vascular diseases and aging $[23,24]$. However, the detrimental effect of GA on obesity and insulin resistance has not yet been studied. Our results confirmed that toxic AGEs (TAGEs) and GA, their precursor, exhibited toxic effects. Therefore, our study on GA is important in relation to obesity and diabetes.

Although adipocyte development plays a crucial role in the pathogenesis of metabolic-related disorders, there are few reports on the effects of AGE on adipocyte adipogenesis and oxidative stress. Many studies related to adipocyte differentiation have focused on the effect of increased adipogenesis or oxidative stress caused by endocrine disruptors and various chemicals [25]. There is a study result that dysregulation of inflammatory adipokines by CML affects insulin resistance in adipose tissue [26, 27]. However, the pathway leading to dysregulation of adipokines due to the influence of AGE has not been elucidated. In addition, it only explains the dysfunction of insulin signaling due to hormone regulation of adipose tissue by CML, but the effect on adipocyte differentiation mechanism and metabolic imbalance is not known yet $[27,28]$. Therefore, our study will play a key 
(A)

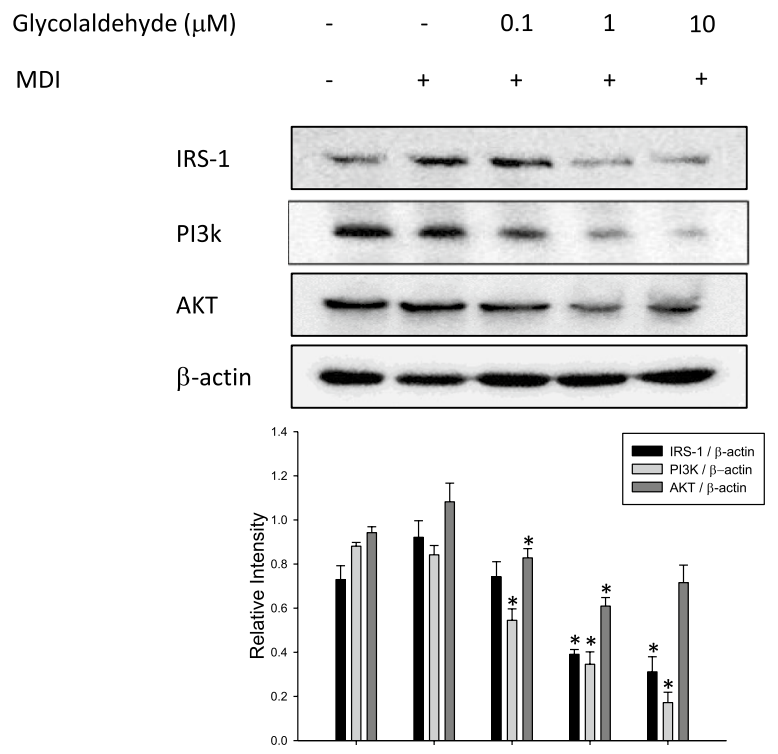

(C)

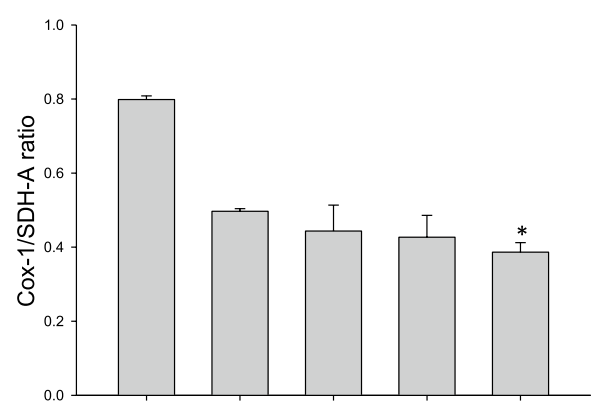

Glycolaldehyde $(\mu \mathrm{M})$

MDI

(E)

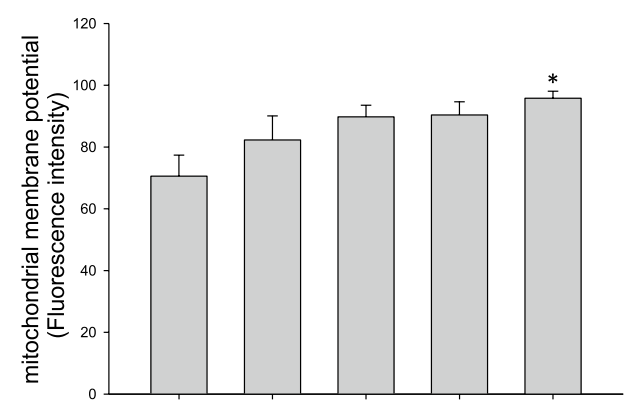

Glycolaldehyde $(\mu \mathrm{M})$

MDI

Fig. 5 (See legend on previous page.)
(B)

$\begin{array}{llllll}\text { Glycolaldehyde }(\mu \mathrm{M}) & - & - & 0.1 & 1 & 10\end{array}$

MDI

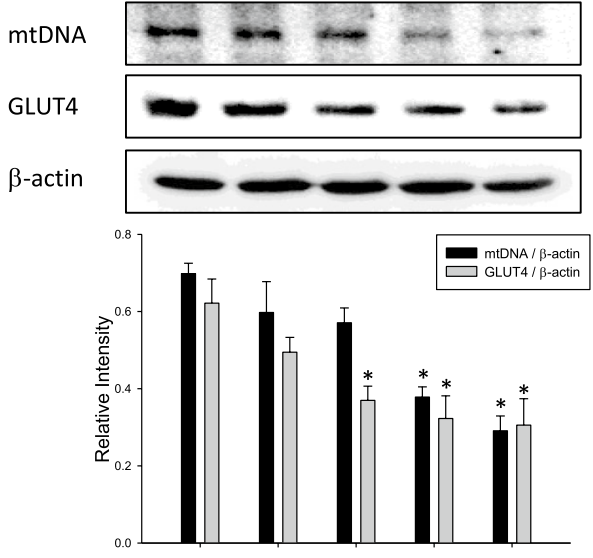

(D)

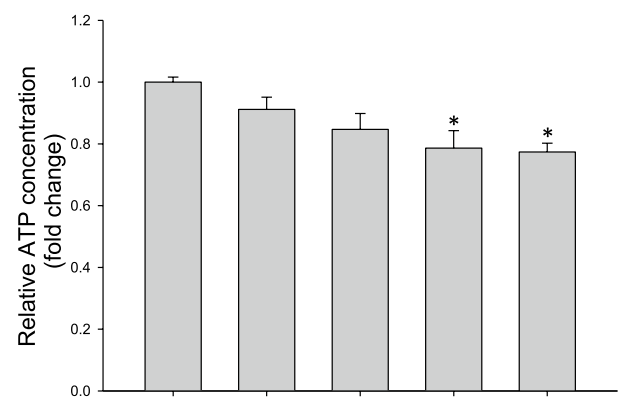

Glycolaldehyde $(\mu \mathrm{M})$

MDI 
(A)

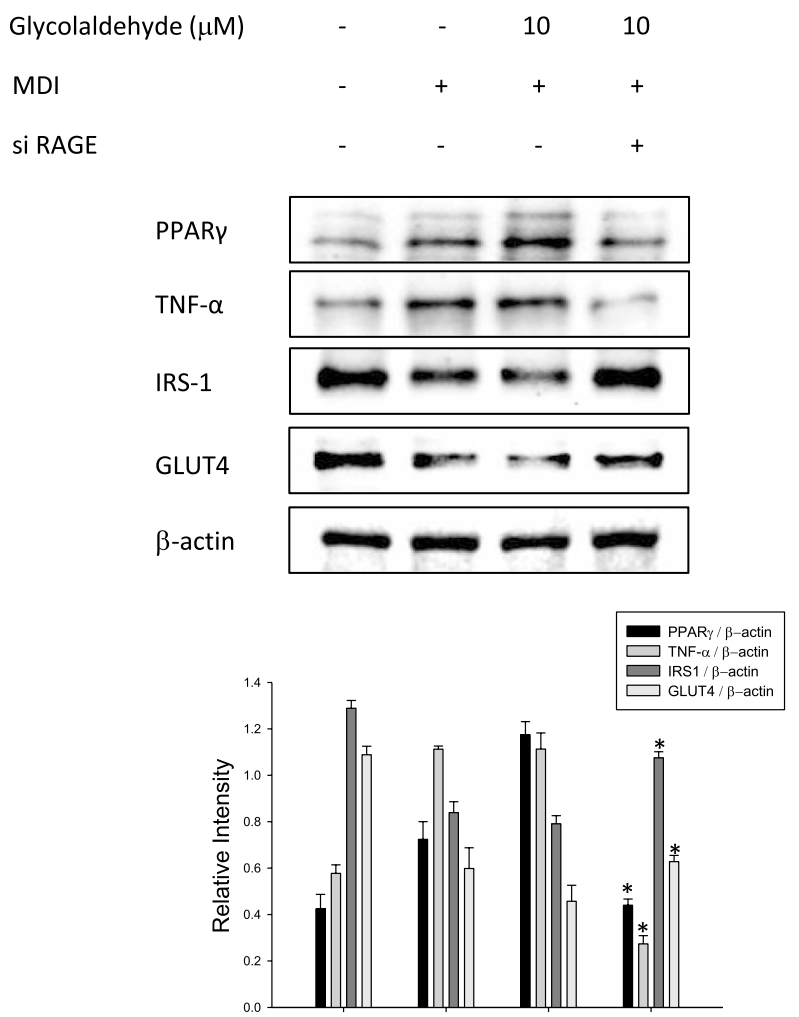

(B)

$\begin{array}{lcccc}\text { Glycolaldehyde }(\mu \mathrm{M}) & - & - & 10 & 10 \\ \text { MDI } & - & + & + & + \\ \text { NAC } & - & - & - & +\end{array}$

Fig. 6 Inhibition of GA-induced adipogenesis and insulin resistance. Effects of RAGE and ROS on inflammatory signaling by GA in adipocytes. 3T3-L1 cells were transfected with control siRNA and specific RAGE siRNA and then treated with GA to check the knockdown of RAGE. A 3T3-L1 cells were transfected with siRAGE and then stimulated with GA (10 $\mu \mathrm{M})$ for $24 \mathrm{~h}$. Expression of PPARy, p-c/EBP $\beta$, TNF-a, IRS-1, and GLUT4 protein was determined by western blot assay. B 3T3-L1 cells were incubated with the ROS inhibitor NAC for $2 \mathrm{~h}$ and then stimulated with GA for $24 \mathrm{~h}$. Whole cell lysates were analyzed by western blot assay. $\beta$-actin protein levels were used as an internal control. Data are expressed as the mean \pm SEM of three independent experiments. ${ }^{*} p<0.05$, significantly different from the untreated group

role in regulating the dysfunction caused by AGE accumulation in the body by confirming the effect of AGE on adipose tissue and the mechanism of AGE on the development of obesity and diabetic diseases.

Adipogenesis is a multi-step process involving a cascade of transcription factors and cell cycle factors leading to the development of adipocytes by regulating gene expression through metabolic and immune changes [29]. White adipose tissue (WAT) plays a central role in regulating energy balance and acts as a secretory and endocrine organ that mediates numerous physiological and pathological processes [30]. Therefore, dysregulation of WAT is an important factor in inducing metabolic diseases such as obesity, diabetes, and arteriosclerosis. The PPARY and c/EBP family, key transcription factors during lipid accumulation, play a key role in the complex transcriptional cascade that occurs during adipogenesis [31]. In addition, various hormones and regulatory signals affect adipogenesis, and the components involved in the interaction between cells and tissues are also closely related to regulating the differentiation process [32, 33]. Understanding the adipose tissue formation process and physiological and pathological mechanisms provides the basis for understanding and controlling metabolic diseases such as diabetes.

We have shown that GA-stimulated increases in RAGE expression and ROS production affect adipocyte differentiation. Therefore, changes in ROS and RAGE levels are important in regulating lipid metabolism. Mitochondrial function is important factor on ROS production and adipocyte differentiation in insulin resistance $[5,8]$. Although previous studies have demonstrated that RAGE is associated with adipocyte differentiation and ROS production promotes adipocyte differentiation, the role of GA, a precursor of AGEs, has not yet been described in adipocyte differentiation and insulin resistance [34-36]. Based on our findings, we propose a mechanism by which GA-induced RAGE expression, ROS production, 
and mitochondrial dysfunction change adipocyte metabolism. Mitochondria are important organs in maintaining energy metabolism and homeostasis, and are thought to be influenced by GA-induced metabolic changes [37, 38]. For this reason, we would like to support this through animal experiments in additional studies. WAT is considered an endocrine organ involved in energy homeostasis as well as fat storage [39]. Present results show that adipocyte differentiation is associated with mitochondrial dysfunction and advances the development of obesity and diabetes. In addition, these results suggest a change in the function and role of mitochondria through the development of adipocytes. Collectively, the study of mitochondrial changes and regulation in metabolic diseases such as obesity and diabetes will be an important strategy for metabolic diseases related to energy metabolism.

Adipogenesis is a necessary process for lipid accumulation, while there are transcription factors necessary for adipocyte differentiation. In addition, adipogenesis causes obesity, which leads to insulin resistance through chronic obesity. Obesity and diabetes can be considered as inflammatory reactions $[40,41]$. The production of inflammatory cytokines is increased through MAPK phosphorylation, a mediator of the inflammatory responses. GA promotes the activation of adipogenic factors in MDI-induced 3T3-L1 cells and increases the proinflammatory cytokines through MAPK phosphorylation $[4,42]$. This suggests that this regulatory mechanism is involved in the stimulatory effect of GA on adipocyte differentiation by an inflammatory response. After the stimulation of lipid formation by MDI, the growtharrested preadipocytes re-enter the cell cycle through several rounds of cell division before the expression of adipogenic genes $[43,44]$. CDK plays an essential role in regulating cell re-entry in the cell cycle, while p21 and p27 function are the major regulators of cell-cycle in the G1 and S phases $[45,46]$. These data showed that GA induces the mitotic clonal expansion of preadipocytes by inducing GA-stimulated G0/G1 phase arrest and the regulation of cell cycle related factor expression.

Furthermore, the mitochondria play a critical role in regulating the oxidative stress and insulin signaling system in obesity and diabetes $[8,9]$. Our results suggest that mitochondrial dysfunction is exacerbated by GA treatment. Various studies have also indicated that ROS production is increased during the AGE-RAGE response and plays a role in controlling insulin signaling through various mechanisms $[34,47]$. However, further investigations are warranted to elucidate these RAGE and ROS interactions as imbalances in the mitochondria or its dysfunction can produce excessive ROS and thus adversely affect downstream signal pathways [48]. Impairment of IRS/AKT/PI3K signaling is strongly associated with decreased insulin sensitivity and glucose uptake [49]. Disorder of IRS/AKT/PI3K signaling is essential for normal glucose and lipid metabolism, and impairment of signaling system leads to insulin resistance, leading to obesity and diabetes $[40,50]$. PI3K, activated by phosphorylation of IRS, is an important regulator of the insulin signaling system [51]. In addition, the regulatory effect of PI3K on lipid metabolism is mediated by AKT [52]. In this study, it was confirmed that changes in IRS/PI3K/AKT regulate the insulin signaling system. Therefore, regulation of insulin signaling by GA appears to be involved in insulin resistance in adipocyte metabolism.

In this study, we showed that GA disrupted the expression of mitochondrial genes and function in adipocytes. We further investigate mitochondrial dysfunction caused by GA and excessive ROS production and found that GA blocked the effects of ROS production and RAGE activation on lipid metabolism in 3T3-L1 cells. These results demonstrate that the protection of mitochondrial function and inhibition of RAGE production play a major role in preventing adipogenesis and insulin signaling of adipocytes.

\section{Abbreviations}

AGE: Advanced glycation end products; RAGE: Receptor for advanced glycation end products; GA: Glycolaldehyde; PPARY: Peroxisome proliferator-activated receptors $\gamma ; \mathrm{c} / \mathrm{EBP}$ : CCAAT enhancer binding protein; CML: $\mathrm{Ne}$-(Carboxymethyl)lysine; CEL: Ne-carboxyethyl-lysine; ROS: Reactive oxygen species; MAPK: Mitogen-activated protein kinase; T2DM: Type 2 Diabetes Mellitus; NOX: NADPH oxidase; aP2: Adipocyte fatty acid binding protein; LPL: Lipoprotein lipase; FAS: Fatty acid synthetase; SREBP-1c: Sterol regulatory element binding protein-1c; MCE: Mitotic clonal expansion; GLUT4: Glucose transporter 4; IRS-1: Insulin receptor substrate 1; PI3k: Phosphoinositide 3-kinase; mtDNA: Mitochondrial DNA; ATP: Adenosine triphosphate.

\section{Acknowledgements}

This research was supported by the Main Research Program (E 0210203) of the Korea Food Re-search Institute (KFRI) funded by the Ministry of Science and National Research Foundation of Korea (NRF) grant funded by the Korea government(MSIT) (NRF-2020R1A2C2012608).

\section{Authors' contributions}

HW, MJ, SK, and YS conceived and designed the experiments. HW, MJ, and JY performed the experiments. HW, MJ, HY, SK, and YS analyzed data and HW, MJ, and SK wrote the manuscript. HW, JY, HY, SK, and YS contributed reagents/materials/analysis tools. All authors have read and approved the final manuscript.

\section{Availability of data and materials}

All data generated or analysed during this study are included in this published article.

\section{Declaration}

\section{Competing interests}

The authors declare that they have no competing interests.

\section{Author details}

${ }^{1}$ Korea Food Research Institute, 245, Nongsaengmyeong-ro, Iseo-myeon, Wanju-gun, Jeollabuk-do 55365, Republic of Korea. ${ }^{2}$ Division of Food Biotechnology, University of Science and Technology, Daejeon, Korea.

Received: 2 April 2021 Accepted: 25 July 2021

Published online: 07 August 2021 


\section{References}

1. Ellis $\mathrm{G}$ (1959) The maillard reaction. Advances in carbohydrate chemistry. 14: Elsevier, pp 63-134

2. Schleicher E, Somoza V, Schieberle PJRAiF, Sciences BSAotNYAo (2008) The Maillard Reaction, p 1126

3. Alexiou P, Chatzopoulou M, Pegklidou K, Demopoulos VJ (2010) RAGE: a multi-ligand receptor unveiling novel insights in health and disease. Curr Med Chem 17(21):2232-2252

4. Zill H, Bek S, Hofmann T, Huber J, Frank O, Lindenmeier M et al (2003) RAGEmediated MAPK activation by food-derived AGE and non-AGE products. Biochem Biophys Res Commun 300(2):311-315

5. Yamagishi S-I, Nakamura K, Matsui T, Ueda S, Fukami K, Okuda SJ (2008) Agents that block advanced glycation end product (AGE)-RAGE (receptor for AGEs)-oxidative stress system: a novel therapeutic strategy for diabetic vascular complications. Exp Opin Invest Drugs 17(7):983-996

6. Bedard K, Krause K-H (2007) The NOX family of ROS-generating NADPH oxidases: physiology and pathophysiology. Physiol Rev 87(1):245-313

7. Boyer F, Vidot JB, Dubourg AG, Rondeau P, Essop MF, Bourdon EJ et al (2015) Oxidative stress and adipocyte biology: focus on the role of AGEs. Oxid Med Cell Longevity 2015:9

8. Coughlan MT, Thorburn DR, Penfold SA, Laskowski A, Harcourt BE, Sourris KC et al (2009) RAGE-induced cytosolic ROS promote mitochondrial superoxide generation in diabetes. J Am Soc Nephrol 20(4):742-752

9. Nass N, Simm AJASAdWzL (2009) Advanced glycation end products (AGEs) in diabetes 65(3):63-75

10. Fajas L, Fruchart J-C, Auwerx J (1998) Transcriptional control of adipogenesis. Curr Opin Cell Biol 10(2):165-173

11. Rangwala SM, Lazar MA (2000) Transcriptional control of adipogenesis. Annu Rev Nutr 20(1):535-559

12. Rosen ED, Spiegelman BM, biology d (2000) Molecular regulation of adipogenesis. Annu Rev Cell Dev Biol 16(1):145-171

13. Emanuela F, Grazia M, Marco DR, Maria Paola L, Giorgio F, Marco BJJ et al (2012) Inflammation as a link between obesity and metabolic syndrome. J Nutr Metab 2012:1-7

14. Dandona P, Aljada A, Bandyopadhyay AJT (2004) Inflammation: the link between insulin resistance, obesity and diabetes. Trends Immunol 25(1):4-7

15. Miyazawa T, Nakagawa K, Shimasaki S, Nagai RJAA (2012) Lipid glycation and protein glycation in diabetes and atherosclerosis. Amino Acids 42(4):1163-1170

16. Rudich A, Tirosh A, Potashnik R, Hemi R, Kanety H, Bashan NJD (1998) Prolonged oxidative stress impairs insulin-induced GLUT4 translocation in 3T3-L1 adipocytes. Diabetes 47(10):1562-1569

17. Wang J, Green P, Simpkins J. Estradiol protects against ATP depletion, mitochondrial membrane potential decline and the generation of reactive oxygen species induced by 3-nitroproprionic acid in SK-N-SH human neuroblastoma cells. J Neurochem. 2001;77(3):804-11.

18. Abu Bakar MH, Cheng K-K, Sarmidi MR, Yaakob H, Huri HZ. Celastrol protects against antimycin A-induced insulin resistance in human skeletal muscle cells. Molecules. 2015;20(5):8242-69.

19. Wang $\mathrm{CH}$, Wang CC, Huang HC, Wei YH (2013) Mitochondrial dysfunction leads to impairment of insulin sensitivity and adiponectin secretion in adipocytes. FEBS J 280(4):1039-1050

20. Abdul-Ghani MA, DeFronzo RA (2008) Mitochondrial dysfunction, insulin resistance, and type 2 diabetes mellitus. Curr Diab Rep 8(3):173

21. O'Brien J, Nursten HE, Ames JM, Crabbe MJC, Crabbe J (1998) The Maillard reaction in foods and medicine. Woodhead Publishing, Sawston

22. Waller GR, Feather MS, editors (1983) The Maillard reaction in foods and nutrition. ACS symposium series (USA). American Chemical Society, Washington, D.C.

23. Van Nguyen CJ, research $f$ (2006) Toxicity of the AGEs generated from the Maillard reaction: on the relationship of food-AGEs and biological-AGEs. Mol Nutr Food Res 50(12):1140-1149

24. Watanabe H, Yoshida Y, Hayase F, editors (2010) Glyceraldehyde-derived advanced glycation end products decrease white adipose tissue weight and downregulate leptin, adiponectin, and macrophage marker. In: 2009 International Symposium on the Maillard Reaction

25. Ghaben AL, Scherer PE (2019) Adipogenesis and metabolic health. Nat Rev Mol Cell Biol 20:242-258

26. Jiang N, Li Y, Shu T, Wang J (2019) Cytokines and inflammation in adipogenesis: an updated review. Front Med 13(3):314-329
27. Gaens KH, Goossens GH, Niessen PM, van Greevenbroek MM, van der Kallen CJ, Niessen HW et al (2014) NE-(carboxymethyl) lysine-receptor for advanced glycation end product axis is a key modulator of obesity-induced dysregulation of adipokine expression and insulin resistance. Arterioscler Thromb Vasc Biol 34(6):1199-1208

28. Gaens KH, Stehouwer CD, Schalkwijk CG (2013) Advanced glycation endproducts and its receptor for advanced glycation endproducts in obesity. Curr Opin Lipidol 24(1):4-11

29. Mandrup S, Lane MD (1997) Regulating adipogenesis. J Biol Chem 272(9):5367-5370

30. Lee B, Shao J (2014) Adiponectin and energy homeostasis. Rev Endocr Metab Disord 15(2):149-156

31. Rosen ED, Walkey CJ, Puigserver P, Spiegelman BM (2000) Transcriptional regulation of adipogenesis. Genes Dev 14(11):1293-1307

32. Rosen ED (2005) The transcriptional basis of adipocyte development. Prostaglandins Leukot Essent Fatty Acids 73(1):31-34

33. Kiess W, Petzold S, Töpfer M, Garten A, Blüher S, Kapellen T et al (2008) Adipocytes and adipose tissue. Best Pract Res Clin Endocrinol Metab 22(1):135-153

34. Newsholme P, Cruzat VF, Keane KN, Carlessi R, de Bittencourt P (2016) Molecular mechanisms of ROS production and oxidative stress in diabetes. Biochem J 473(24):4527-4550

35. Castro JP, Grune T, Speckmann BJB (2016) The two faces of reactive oxygen species (ROS) in adipocyte function and dysfunction. Biol Chem 397(8):709-724

36. Shadel GS, Horvath TLJC (2015) Mitochondrial ROS signaling in organismal homeostasis. Cell 163(3):560-569

37. Choo H-J, Kim J-H, Kwon O-B, Lee C, Mun J, Han SS et al (2006) Mitochondria are impaired in the adipocytes of type 2 diabetic mice. Diabetologia 49(4):784-791

38. Medina-Gómez G (2012) Mitochondria and endocrine function of adipose tissue. Best Pract Res Clin Endocrinol Metab 26(6):791-804

39. Cedikova M, Kripnerová M, Dvorakova J, Pitule P, Grundmanova M, Babuska $\checkmark$ et al (2016) Mitochondria in white, brown, and beige adipocytes. Stem Cells Int. https://doi.org/10.1155/2016/6067349

40. Pérez MR, Medina-Gómez GJ (2011) Obesity, adipogenesis and insulin resistance. Endocrinol Nutr 58(7):360-369

41. Engin A (2017) The pathogenesis of obesity-associated adipose tissue inflammation. Obesity and lipotoxicity. Springer, Berlin, pp 221-245

42. Bost F, Aouadi M, Caron L, Binétruy BJB (2005) The role of MAPKs in adipocyte differentiation and obesity. Biochimie 87(1):51-56

43. Lee H, Lee YJ, Choi H, Ko EH, Kim J-W (2009) Reactive oxygen species facilitate adipocyte differentiation by accelerating mitotic clonal expansion. J Biol Chem 284(16):10601-10609

44. Tang Q-Q, Otto TC, Lane MD (2003) Mitotic clonal expansion: a synchronous process required for adipogenesis. Proc Natl Acad Sci 100(1):44-49

45. Li X, Kim JW, Grønborg M, Urlaub H, Lane MD, Tang Q-Q (2007) Role of cdk2 in the sequential phosphorylation/activation of C/EBP $\beta$ during adipocyte differentiation. Proc Natl Acad Sci 104(28):11597-11602

46. Tang Q-Q, Otto TC, Lane MDJ (2003) CCAAT/enhancer-binding protein $\beta$ is required for mitotic clonal expansion during adipogenesis. Proc Natl Acad Sci 100(3):850-855

47. Nugent MM, He JC (2018) How AGEs cause disease: cellular mechanisms, p

48. Russell EG, Cotter TG (2015) New insight into the role of reactive oxygen species (ROS) in cellular signal-transduction processes. Int Rev Cell Mol Biol 319:221-254

49. Hotamisligil G (2000) Molecular mechanisms of insulin resistance and the role of the adipocyte. Int J Obes 24(4):S23-S27

50. Pérez C, Fernández-Galaz C, Fernández-Agullo T, Arribas C, Andrés A, Ros $M$ et al (2004) Leptin impairs insulin signaling in rat adipocytes. Diabetes 53(2):347-353

51. Boura-Halfon S, Zick Y (2009) Phosphorylation of IRS proteins, insulin action, and insulin resistance. Am J Physiol Endocrinol Metab 296(4):E581-E591

52. Huang X, Liu G, Guo J, Su Z (2018) The PI3K/AKT pathway in obesity and type 2 diabetes. Int J Biol Sci 14(11):1483

\section{Publisher's Note}

Springer Nature remains neutral with regard to jurisdictional claims in published maps and institutional affiliations. 